\title{
Gênero de atividades profissionais, variantes estilísticas e genericidade em clínica atividade
}

\author{
Danielle Ruelland-Roger ${ }^{1}$ \\ Conservatoire National des Arts et Métiers (Paris, França)
}

\begin{abstract}
O objetivo da clínica da atividade é propor um quadro para que o trabalho possa ser ou vir a ser um objeto de pensamento para os próprios profissionais, a fim de permitir-lhes desenvolver seu poder de agir. A intervenção aqui apresentada destaca que, em um contexto de análise de suas atividades cotidianas pelos próprios profissionais, é a transformação, pelo exercício diário da profissão, pelas variantes estilísticas do gênero - aqui, os professores de matemática que ensinam em universidades na França - que produzem um efeito de genericidade, levando à aparição de novas formas do gênero profissional. Em um primeiro momento, o artigo apresentará os conceitos postos a prova por essa pesquisa. Então, deter-se-á em mostrar, em um caso específico, como esses conceitos permitem compreender os caminhos que levam os profissionais envolvidos a modificar suas maneiras de conceber e realizar o trabalho e, assim, revitalizar os objetivos de suas atividades profissionais. E como, também, esses profissionais adquiriram uma nova capacidade, pessoal e coletiva, de questionar suas atividades e profissões.
\end{abstract}

Palavras-chaves: Atividade, Gênero de atividades profissionais, Variantes estilísticas de gênero..

Professional activities genre, stylistic variations and generecity in clinic of activity

The objective of the clinic of activity is to propose a framework so that work can be or become an object of reflection for the professionals themselves, in order to allow the development of their power to act. The field intervention presented here highlights that, in a context of analysis of everyday activities by the professionals themselves, it is transformation, by the daily exercise of their profession, by stylistic variations of the gender specifically that of mathematics teachers of universities in France - that produces an effect of genericity, leading to the emergence of new forms of professional gender. At first, the concepts tested by the research will be presented in the article. Then, it will focus on showing, in a specific case, how these concepts enable the understanding of the processes conducting professionals to changes in ways of conceiving and performing the work and, thus, renewing the objectives of their professional activities. And how, in addition, these professionals acquired a new, personal and collective competence of questioning their activities and professions.

Keywords: Activity, Professional activities gender, Stylistic variations of gender.

$\mathrm{N}$ a clínica da atividade, o objetivo de transformação das situações de trabalho se distingue das estratégias clássicas de intervenção que conduzem a preconizações. O que importa é propor um plano para que o trabalho possa tornar-se um objeto de pensamento para os próprios profissionais a fim de permitir-lhes desenvolver o poder de agir. Então, para o intervenienteclínico, propõe-se a questão dos conceitos que devem ser utilizados e que sempre estão sujeitos às surpresas da realidade (Clot \& Faïta, 2000). Trata-se pois de um trabalho teórico específico que conduz a elaborar, entre outras, noções tais como tipo de atividades profissionais, variantes estilísticas do gênero e genericidade da atividade.

Num primeiro tempo, serão apresentados esses conceitos e o seu uso em clínica da atividade. Depois, iremos nos dedicar a uma intervenção de campo. Esta vai mostrar que, num contexto de análise de sua atividade pelos próprios profissionais - neste caso, professores de ensino médio na França -, é a mudança, das variantes estilísticas do gênero, que produz um efeito de genericidade, que tende ao desenvolvimento do gênero profissional.

1 Membro da equipe de Clínica da Atividade e da Psicologia do Trabalho (CRTD) do Conservatório Nacional de Artes e Ofícios (CNAM). 


\section{O gênero de atividades profissionais em clínica da atividade}

O uso da noção de gênero em clínica da atividade apoia-se em três fundamentos. $\mathrm{O}$ primeiro é a obra de Mikhail Bakhtin (1984, p. 285-287), que chama a atenção para o fato de que um enunciado, verbal ou escrito, só é possível graças a gêneros de discursos que permitem ao sujeito dispor de um estoque de enunciados esperados do qual ele se serve para organizar sua fala e fazer-se entender pelos outros. A análise do trabalho constitui um segundo fundamento. A ergonomia mostra o distanciamento entre o trabalho prescrito e o trabalho realizado. A psicopatologia ressalta que há atividades contrariadas na ação de trabalho e que esse negativo pode dar origem a perda de sentido e sofrimento, mas pode ser também fonte de energia e de mobilização. O terceiro fundamento é a concepção do social na teoria do desenvolvimento de Vygotsky. Para este, o social está presente mesmo quando estamos sós, não fora de nós, nem mesmo entre nós, mas em cada um de nós (Vygotsky, 1935/1994). Foi levando em consideração estas três fontes que se elaborou, em clínica da atividade, o conceito de gênero de atividades profissionais (Clot \& Faïta, 2000).

\section{O gênero de atividades profissionais}

Trabalhar é encontrar maneiras de utilizar as coisas e as pessoas para fazer o que é preciso quando nos encontramos mergulhados em situações nas quais se catapultam fenômenos contraditórios que incitam a agir no mesmo instante, seja de um modo ou de outro, ou de um terceiro etc. É aí que o gênero de atividades profissionais é funcional na medida em que fornece, ao mesmo tempo, dificuldades e recursos aos profissionais para controlar seus atos na direção dos objetos e dos sujeitos. Como ocorre nos gêneros de discursos, é uma espécie de estoque, mas, desta vez, de maneiras diversificadas de pensar e de fazer o trabalho, por um momento estabilizadas e admitidas entre os pares num dado meio profissional. Os trabalhadores dispõem dele para poder agir, pois, "se fosse preciso criar, todas as vezes que agimos, cada uma de nossas atividades, o trabalho se tornaria impossível" (Clot \& Faïta, 2000, p. 11). O gênero oferece suportes para conseguir fazer o que é preciso, para fazer o que desejaríamos, por vezes sem conseguir, ajudar a refazer o já foi feito, evitar fazer sem tê-lo desejado, etc. Ele limita, para cada profissional, os riscos da perda de tempo nas maneiras de fazer, cansativas, pouco eficientes e nem sempre eficazes, entre a tarefa prescrita e a atividade individual. Assim, o gênero pode contribuir para que as atividades contrariadas possam tornar-se fonte de energia para desenvolver o poder de agir.

É assim que, num meio profissional, consegue-se, mais ou menos, reorganizar a tarefa prescrita pela instituição. $\mathrm{O}$ gênero desempenha o papel de um intermediário social entre o indivíduo no trabalho e as instâncias organizadoras e prescritivas desse trabalho. É, "de algum modo, a parte subentendida da atividade daquilo que os trabalhadores de um determinado meio conhecem e veem, esperam e reconhecem, apreciam e temem" (Clot \& Faïta, 2000, p. 11). Se examinarmos mais de perto o lugar do gênero de atividades profissionais na atividade individual, triplamente dirigida ao seu objeto, aos outros que compartilham o mesmo objeto de atividade, e ao próprio sujeito, o gênero se mostra como uma espécie de responsável coletivo dessa atividade individual, responsável que não é externo aos profissionais, nem unicamente entre eles, mas também em cada um deles.

\section{"Apropriação" do gênero e variantes estilísticas do gênero}

Então, a "apropriação" do gênero pelo sujeito não é o fato de ele apropriar-se de uma determinada série de ações obrigatórias fixas. O gênero não é um conjunto de normas externas a ele e às quais deve se conformar. Há que se entender sua apropriação como o acesso a algo que 
poderíamos chamar de um "enquadramento" que permite ao sujeito dispor de esquemas operatórios e simbólicos já constituídos para constituir outros em situação. É o dado a se recriar na ação. Aquele que trabalha age a partir de um gênero, mas ele o ajusta e o aperfeiçoa.

Assim sendo, o gênero está sempre inacabado. Mesmo que seja possível reinvesti-lo em cada situação de trabalho, ele só vai tomar sua forma acabada nos traços particulares, contingentes, únicos e não reiteráveis que definem cada situação vivida (Clot \& Faïta, 2000). Para melhor desvencilhar-se nos conflitos de sua atividade (Clot, 1999a), os sujeitos vão buscar recursos no gênero, mas também e simultaneamente libertam-se dele, criam-lhe variantes estilísticas. Esses estilos pessoais têm origem numa atividade que, sempre dirigida ao objeto e aos outros, é também dirigida a si mesmo. O sujeito não pode calar e nem fazer calarem-se os esquemas operatórios, perceptivos, corporais, emocionais ou ainda relacionais e subjetivos sedimentados durante a sua vida. É como se fosse um potencial de "prontidão para agir" de acordo com a avaliação da situação. Trata-se da experiência do sujeito que pode facilitar ou desencaminhar a sua ação. Em contato com o real, os esquemas dessa experiência estilizam o gênero profissional, solicitam o novo repetindo o antigo.

Daí resulta uma dinâmica das relações entre gênero e variantes estilísticas em que o gênero, de recurso que é inicialmente, torna-se fonte da atividade do sujeito que, para agir, remodela o gênero. Daí também resultam divergências entre variantes que se defrontam, o que é o melhor sinal da vitalidade de um gênero.

\section{Gênero e meio profissional}

Diante dos imprevistos do real, importa que o gênero tenha a flexibilidade e o enquadramento que permitam, a cada um, ir buscar, nas maneiras de fazer já constituídas, aquelas que podem servir-lhe para constituir uma nova forma de ação. $O$ gênero de um meio profissional se mantém, pois, e "aqueles que agem devem poder jogar com o gênero ou, mais exatamente, conciliar habilmente as diferentes variantes que animam a vida do gênero. É aquele processo de metamorfose dos gêneros, promovidos à categoria de objetos da atividade, e que recebem novas atribuições e funções para agir, conservando a vitalidade e a plasticidade do gênero" (Clot \& Faïta, 2000, p. 15).

"Mas a morte sempre pode insinuar-se na vida" (Clot, 2008, p. 160). O gênero pode petrificar-se. A história de um meio profissional pode cair na armadilha do passado. Então, entravada pela rigidez de um gênero que só é o responsável por esquemas operatórios e simbólicos que se manifestam na repetição de uma versão única, a atividade individual, para desenvolver-se, tem de superar uma sobrecarga de obstáculos. Por estar desajustado, o gênero pode causar embaraços. Então, provoca mal-entendidos no diálogo entre profissionais e fracasso na ação. Nenhum gênero de atividades profissionais está a salvo de semelhante destino, na medida em que toda sociedade se transforma, provocando mutações mais ou menos rápidas e profundas das situações de trabalho e transformações na organização oficial do trabalho. Como hoje em dia isso é frequente, essas mutações podem ter efeitos patogênicos quando se torna difícil, para os profissionais, chegar a um acordo sobre obrigações compartilhadas e cada qual vive quase um enfrentamento entre suas maneiras pessoais de fazer e as prescrições.

Uma vez que ele só se realiza e se revela nas múltiplas variantes que se formam durante sua história, o gênero do meio profissional só conserva seu papel de recursos na atividade dos sujeitos quando permite as recriações estilísticas pelo funcionamento da dinâmica do gênero e de suas variantes. Isso ocorre com diálogos diversificados, informais ou formais, entre profissionais que podem chegar à validação coletiva de novas variantes estilísticas, melhor ajustadas às novas condições da ação. Senão, é grande o risco de que o gênero profissional se

2 Em francês, contenance. 
torne encapsulado, que o poder de agir, pessoal e coletivo se encontre apanhado numa espiral de subdesenvolvimento.

\section{A genericidade da atividade}

Falamos de genericidade da atividade profissional para caracterizar seu poder de, em maior ou menor grau, transformar o gênero. A atividade de um sujeito será, mais ou menos, fator de genericidade naquilo que, na ação, ele mobilize algumas das maneiras de fazer genéricas e que deixe outras de lado, que as transforme. Em outras palavras, efetua-se, no caso, um trabalho de afinamento que permite vencer certa opacidade da atividade. É uma contribuição estilizada para o gênero do meio profissional na medida em que a transformação realizada pode ser aceitável pelos pares como contribuinte para o desenvolvimento do gênero.

Nesse processo, as repetidas trocas de informação com o trabalho dos outros desempenham um papel decisivo. Dessas trocas recíprocas, formais e informais, entre profissionais depende o funcionamento das variantes estilísticas do gênero, essencial para preservar-lhe a "elasticidade" e assegurar-lhe o desenvolvimento. É o que permite a cada um evitar o risco de se encontrar prisioneiro de uma alternativa, sem muito futuro, entre prescrição oficial e o que seria, então, simples transgressão pessoal.

Mas é preciso que as situações de trabalho favoreçam, ou pelo menos permitam, as trocas necessárias ao desenvolvimento do gênero. Nem sempre é esse o caso. Para citar apenas um exemplo, a orientação atual escolhida na França pela instituição responsável pelo ensino recomenda múltiplas reuniões entre membros de um estabelecimento escolar. Mas, na maioria das vezes, essas reuniões são constituídas simplesmente por "coleções" de professores visando tarefas técnicas e precisas. Esse dispositivo institucional tende a sufocar o desenvolvimento do gênero, pois deixa, aos profissionais, pouquíssima disponibilidade para reais confrontações e trocas de informações acerca das maneiras de fazer de cada um. O responsável coletivo pela atividade individual fenece no interior dos sujeitos e provoca um aumento das dificuldades para ensinar, uma culpabilização, um desgaste excessivo dos professores.

\section{A clínica da atividade: uma contribuição ao trabalho de desenvolvimento do gênero}

O projeto da clínica da atividade é prestar assistência a um meio profissional na retomada de um trabalho de aperfeiçoamento genérico.

A tarefa proposta aos profissionais envolvidos nesse projeto consiste em elucidar, para si mesmo e para os outros, as questões que surgem durante as sequências de atividade tais como aparecem nos vídeos gravados ou em instruções dadas a um sósia. ${ }^{3}$ Para o sujeito observado, trata-se de uma atividade em si mesma e não somente de um meio de acesso a sua atividade principal. Porque, nos diálogos que se realizam, o profissional procura "levar o outro a pensar, a sentir e a agir de acordo com a sua própria perspectiva” (Clot \& Faïta, 2000, p. 32). Assim, quando está em observação, com um ou mais colegas, é levado a olhar para o que se vê fazer "com os olhos" por vezes muito "surpresos" de outros que estilizaram o gênero de seu meio profissional em variantes diferentes, até mesmo desenvolveram maneiras estranhas ao gênero dominante do meio profissional. Observar sua própria atividade com outros e através deles conduz, na grande maioria dos casos, a examinar como foi possível servir-se dos recursos oferecidos pelo gênero disponível, acomodar-se a eles, ou, ao contrário, deixá-los de lado. Daí pode resultar, para todos, um novo progresso do trabalho de afinamento genérico na ação.

3 Para satisfazer ao desejo de precisão do leitor, vale mencionar aqui o artigo de Jean-Luc Roger a respeito dos métodos em clínica da atividade publicado nesta mesma edição dos CPST. 
Nesse caso, a atividade do interveniente-clínico consiste em estabelecer e manter uma relação dialógica que, por dizer respeito às maneiras de tomar em consideração as coisas e as pessoas em situação de trabalho, evite confronto linguageiro unicamente mobilizado pelo presente da interlocução. Trata-se de estimular o desenvolvimento em diálogos e em controvérsias, diálogos internos reativados ou provocados pelas autoconfrontações. É importante também tentar iniciar uma atividade de desligar e religar das maneiras de enfrentar os desafios da situação de trabalho observada. Tentamos, pois, incitar uma atividade compartilhada que mobilize não só aquele que vemos trabalhar, mas também os colegas que se encontram, então, enfrentando a reativação, em si mesmos, daquilo que fizeram e viveram, muitas vezes bem recentemente, em situações análogas. A abordagem de tais situações sempre mostra algo da variante estilistica da atividade do profissional e essa atividade de desligar-religar contribui para um trabalho de afinamento da estilística do gênero.

\section{O jogo do gênero numa intervenção com professores de matemática no ensino médio}

A história do ensino de matemática na França na segunda metade do século XX está marcada pelos efeitos da própria história das ciências matemáticas. Um dos impactos marcantes dessa história foi a introdução, antes de 1968, de uma reforma que se desejou mais em conformidade com uma visão axiomática da matemática: a "matemática moderna". Paralelamente, a fim de acompanhar essa reforma, foram criados os IREMs (Institut Régionaux de Recherche sur l'Enseignement des Mathématiques) [Instituto Regional de Pesquisa sobre o Ensino de Matemática], que sobreviveram, até a atualidade, ao fracasso posterior da reforma da "matemática moderna". Instalou-se e desenvolveu-se uma espécie de "trabalho sobre o trabalho do ensino da matemática" dentro dos grupos constituídos por professores do ensino médio e de alguns universitários. Esse "trabalho sobre o trabalho" fundamentou-se numa pesquisa em didática da matemática cujas fontes foram trabalhos efetuados em psicologia a respeito da atividade e seu desenvolvimento.

Mais tarde, nos anos 1980, foram criados os IUFMs (Institut Universitaire de Formation des Maîtres). No que tange à matemática, a formação inicial dos futuros docentes se abriu mais e ao mesmo tempo para os meios da pesquisa e para o meio do ensino. Os novos formadores, procedentes tanto da pesquisa em didática quanto das escolas, introduziram em sua atividade formadora as experiências dos trabalhos tanto dos IREMs quanto dos didatas. Foi um momento muito particular em que as prescrições institucionais puderam ser reinterpretadas, particularmente no seio dos IREMs e de sua rede nacional, pelos próprios profissionais, em novas variantes estilísticas do gênero. Elas se propagaram diversificando-se em boa parte do meio profissional. Até então, o gênero profissional amplamente compartilhado - e ainda parcialmente presente - organizava-se em torno do curso de extensão universitária, de exercícios de aplicação e de problemas fechados e muito normatizados. Ele deixa totalmente a cargo dos alunos uma parte importantíssima do processo de apropriação dos conhecimentos e dos métodos. Para combater os fracassos que isso parece ocasionar, desenvolveu-se uma nova versão genérica caracterizada por uma forma, para os professores, de olhar diferentemente a atividade dos alunos. Por exemplo, objetivando a apoiar a mobilização dos alunos para um trabalho de apropriação até então muito subestimado, enfatizou-se o interesse deles em descobrir novos objetos matemáticos solucionando situações-problemas mais ou menos abertas. A seu modo, a instituição irá inspirar-se progressivamente nisso para estabelecer os programas, as instruções dadas aos docentes, os conteúdos da formação.

Na ocasião da nossa pesquisa, o meio profissional dos professores de matemática do ensino médio é muito heterogêneo quanto às suas relações com as diversas versões do gênero. 
Para alguns, a nova versão é vivida como algo distante, sem que seja realmente evidente tratarse de um verdadeiro recurso para levar a viver melhor o seu ofício. Para outros, são reais recursos, mas é muito difícil dividi-los com os colegas.

Tudo acontece como se fossem dois gêneros diferentes, estranhos um ao outro, que não têm muito a dizer-se. Mas, com maior frequência, essa dualidade do gênero originária da história recente de cada um é um desafio da atividade cotidiana, como veremos no caso de Denis.

\title{
Denis, seus dilemas de trabalho e a dualidade do gênero
}

Quando a intervenção tem início, Denis (Roger, 2007), está no seu quarto ano de magistério. Ele é filmado numa classe de sexta série quando está ensinando a noção de área de uma figura. Ao se ver, pela primeira vez, diante da gravação de sua aula, dá-se conta de que realmente não deixa tempo aos alunos para pesquisarem e fazerem o que ele havia pedido. Ocorre, então, uma forte irritação, acentuada por sua atitude e sua fala, e que o intervenienteclínico observa. Então, Denis pausa a exibição do vídeo no momento em que a imagem mostra os alunos tentando fazer uma colagem solicitada pouco antes, enquanto ele dá prosseguimento à aula:

\begin{abstract}
Ali, estou vendo que eles ainda estão colando enquanto eu vou explicando. Não sei se o que estou contando naquele momento tem muita serventia! Acabo de dizer-lhes para colar imediatamente! Peço para colarem enquanto estão fazendo! Ali, vou depressa demais porque eles ainda estão colando enquanto estou fazendo a síntese do exercício com eles! É difícil, para mim, ficar esperando enquanto eles estão fazendo, isto é, exceto quando fazemos aulas de exercício, mas, quando temos uma discussão, eu deveria saber ficar calado cinco minutos, dando tempo para que eles acabem de colar e que troquem de caderno, não é mesmo! Mesmo quando eles fazem isso, eu tenho de ficar falando com eles!
\end{abstract}

Denis procura explicar esse dilema de trabalho entre o ritmo dos alunos e o ritmo que ele impõe na aula:

É a minha experiência de aluno. Não quero que a atividade, não quero dizer necessariamente uma atividade de início de curso, como tendemos a chamar, de exercícios preparatórios, mas a atividade matemática... Tenho medo da atividade matemática em que o menino não é suficientemente orientado no plano das questões e não sabe aonde queremos chegar... e que ele desista. Porque eu vi, talvez não necessariamente em matemática, mas em outras matérias quando eu era aluno: você não sabe aonde se quer chegar, aonde querem chegar e de repente a gente desiste e faz outra coisa... É por isso que eu faço muitas perguntinhas assim, diretas e simples, globalmente simples como essa. Eu ligo, e é também a minha experiência de professor, quando pude ver, em algumas classes, muita pretensão em relação ao nível da meninada. Eu tinha coisas complicadas demais em matéria de atividade. Eu queria demais, talvez, fazer uma atividade como nos ensinam no IUFM: ela tem de ser longa e temos de colocar um pouco de tudo o que virá no curso. Os garotos, no fim de duas questôes, não sabem mais aonde queremos chegar e depois, eles não compreendem mais, começam a conversar e a fazer outra coisa, sabe! Então, é por isso que é rápido e isso parte sempre de mim. Para mim, a grande questão aberta em que os alunos devem arrumar tudo, tenho medo de não saber orientar ou de só saber orientar com os bons.

É evidente que, para Denis, a nova versão do gênero, tal como ele viu ser posta em prática por alguns no IUFM, ou, pelo menos, como ele a compreende, não serve como recurso; em vez disso, é causa de dificuldades, até mesmo de fracasso. Diante das dificuldades que a gestão das classes traz atualmente, ele se inspira, mais ou menos conscientemente, na sua vivência de aluno. Por isso, ele tende a deixar de lado tudo aquilo que "não é suficientemente orientado no plano das questões e o menino não sabe aonde queremos chegar... e que ele desista". Ao 
fazer isso, ele se aproxima, num estilo muito pessoal marcado pela pressa, da matriz genérica tradicional, em que exercícios e problemas se efetuam sob a direção estrita do professor.

\section{Da responsabilidade pessoal em questóes de profissão}

Num primeiro tempo, Denis procura espontaneamente explicar, por comportamentos pessoais, aquela situação que tanto o incomoda:

Isso não me surpreende porque eu sou assim. Sou extremamente... Na vida, sou impaciente, muito, muito impaciente, e na aula é a mesma coisa. Tem de andar depressa, mesmo nas perguntas que faço... E depois, é muito difícil para mim que sejam eles que mandem, que sejam eles. Tudo tem de partir de mim! Sou eu que tenho de perguntar... Sim, acho que é isso mesmo, sou demasiadamente diretivo, certamente diretivo demais no meu jeito de fazer... $\mathrm{Na}$ verdade, gosto que a aula siga num ritmo bastante acelerado em que eles não têm tempo, quero dizer, em que eles quase não têm tempo de fazer outra coisa além de responder as minhas perguntas e fazer os exercícios que passo.

Todos aqueles comportamentos pessoais the parecem acentuados por sua falta de experiência de professor novato:

Bem, tenho só 3 ou 4 anos de experiência, não é grande coisa. Quando preparo os exercícios com antecedência, não consigo enxergar quais serão as dificuldades que eles vão ter... Honestamente, eu tateio... Como não consigo prever antes, formulo as questões diretamente... Quando começo a formular um questionário em minha casa à noite, vou fazer esta, aquela, aquela pergunta e naquela ordem. Se insisto nisso, não terá sentido algum em relação ao que eles compreenderam do exercício. Então, como a coisa me vem diretamente, mesmo que eles estejam fazendo outra coisa, vou fazer-lhes a pergunta.

Entretanto, a reflexão não para por aí. $\mathrm{O}$ interveniente-clínico incita-o a prosseguir propondo-lhe uma outra maneira de dizer o que foi dito. Mais precisamente, leva-o a expor a situação de modo menos global, a separar-lhe os componentes diferenciáveis.

Interveniente: Isso significa que, não sei como poderíamos dizer, porque você diz duas que um pouquinho...

Denis: Contraditórias!

Interveniente: Não contraditórias, mas diferentes, em dois campos diferentes. Você diz: não quero que as perguntas venham deles, portanto você quer reprimir as reflexões deles sobre aquilo que estão fazendo em matemática. E depois, você tem outra coisa, você diz: não quero que eles possam estar em outra parte que não seja a matemática. É isso?

Denis: É isso.

Interveniente: Para você, é a mesma coisa, ou são duas coisas que são diferentes e que se misturam?

Denis: Para mim, elas se misturam. Quando quero que elaboremos um raciocínio ou formemos uma noção com eles, quero que ela venha deles no sentido em que quero que respondam as minhas perguntas... Quer dizer que eu, o princípio do problema completamente aberto, ou então a atividade completamente aberta, em que toda a construção tem de vir deles, tenho medo que isso só dê certo com alguns alunos.

Esse primeiro desligar-religar conduz a uma nova interpretação que já não enfatiza tanto os problemas de gestão da classe, nem comportamentos pessoais quanto à questão central da atividade real do aluno e o seu lugar na aprendizagem, tal como a trata a nova versão genérica. Esse problema reaparece um pouco depois, quando Denis assiste novamente ao 
episódio da colagem, dessa vez com uma colega. Esta, Gaëlle, é mais antiga que ele na profissão, uma vez que leciona há mais de dez anos. Ela não está familiarizada com a nova versão do gênero, senão formalmente, por meio do que foi retomado nos programas e instruções oficiais. Enquanto Denis volta a falar do caso da colagem, Gaëlle declara que se viu, nas imagens de sua própria aula, proceder de forma sensivelmente idêntica. Entretanto, ela o viu de maneira mais calma, na medida em que encontrou os meios de administrar mais ou menos a situação: "Mesmo agora, quando eles estão copiando, se for preciso dizer-lhes uma coisa importante, peço que deixem o lápis para que escutem. Se você quiser, eu formalizo; ouço-me dizendo: bom, vou esperar que vocês acabem de copiar ou de colar". Para ela, outra maneira de reagir é "postar-se à mesa" quando "lhes demos um exercício" mesmo que "se tenha a impressão de que eles não vão fazer nada". Contudo, isso não resolve a questão da natureza e do lugar da atividade dos alunos. O diálogo que se inicia, então, entre os dois professores, tenta analisar essa questão profissional examinando os diversos elementos das situações que, quando envolvidos nelas, os conduzem a instalar em suas classes um ritmo demasiado rápido para que a maior parte dos alunos possa ficar efetivamente ativa.

\section{Da análise e da mudança de estilo...}

Entretanto, nessa fase, nem Denis nem Gaëlle encontram, nas diversas facetas dos gêneros profissionais, os recursos necessários para resolver, nem mesmo para enfrentar esse problema. De certo modo, eles permanecem influenciados pela matriz tradicional do gênero, que reserva ao professor o controle detalhado da atividade dos alunos. É o que lhes permite sustentar as situações. Mas, embora interpelados, cada um ao seu modo, pela nova versão genérica que tende a desenvolver a atividade própria do aluno, eles não conseguem progredir realmente sobre essa questão.

A intervenção, para Denis e Gaëlle, consistiu classicamente em clínica da atividade, numa atividade de observação dialógica de suas maneiras de agir. Inicialmente em autoconfrontações simples e cruzadas, depois em reuniões com cinco colegas. Mas foi dada também a eles a ocasião de trabalhar de forma cruzada, com outro grupo de colegas no qual se encontrava uma professora, Martine, muito a par dos conteúdos e métodos característicos da nova versão do gênero. A ampliação assim organizada do diálogo foi a ocasião de "ver" uma forma de agir estruturada em torno da atividade real do aluno. $O$ que foi decisivo foi confrontar-se efetivamente, num quadro de clínica da atividade, com esta outra maneira de ensinar. Denis percebe-o bem:

Eu me dou conta de que a cada vez [estas maneiras de agir] eu já tinha ouvido falar delas antes. Martine já tinha me dito. Quando eu estava iniciando, fiz um estágio orientado por ela. Eu sabia como funcionava. Ela, no fundo da classe etc. Mas isso nunca teve o mesmo impacto que os vídeos. É o fato de se ver agir e de debater a respeito.

Gaëlle, por sua vez, ressalta o que lhe propiciou a atividade de observação dialógica do curso de Martine:

Para mim, foi muito do que eu vi e discuti no curso de Martine, nas suas classes de 6 $6^{\underline{a}}$ e de $5^{\underline{a}}$ que me fez progredir. Muitíssimo. Por me dizer que suas regras do debate em matemática, como ela as fizera, funcionavam. Então, é certo, isso dependia dela, mas não somente dela! Poderia também ser transferido e eu podia fazer alguma coisa.

Uma nova análise dos vídeos irá mostrar que aquela sucessão de fases de trocas dialógicas provoca um diálogo interior, uma conduta reflexiva que persistiu por longo tempo, muito além dos lugares e dos momentos dedicados explicitamente à intervenção clínica. Esse processo permitiu a ambos mudar as maneiras de agir. Então, Gaëlle declara: "Não peço mais, 
dou dois minutos, prefiro usar o tempo necessário para que a coisa comece". Dessa forma, ela prossegue o trabalho reflexivo sobre o ritmo que estabeleceu nas suas classes e anota mudanças entre o que ela se vê fazer no vídeo e o que pensa fazer doravante com seus alunos. "Finalmente, já não tenho a impressão de ter perdido o ritmo, mas a impressão de fazer as coisas com mais serenidade, usando o tempo de fazê-las. E a isso, por sua vez, Denis replica: "Comigo é mesma coisa".

De fato, essa mudança de atitude quanto ao ritmo da aula remete mais fundamentalmente a uma nova maneira de conceber e de organizar a aprendizagem e a atividade dos alunos. Gaëlle analisa assim:

Naquele momento, eu deveria dizer-me que era preciso que eles vissem muitos exemplos... Agora, eu digo: Quando eu faço um exemplo, e se eles compreenderam que, para calcular a área de uma figura, eles podem deslocar uma parte dela para obter uma figura cuja área pode ser calculada facilmente, não há necessidade de fazer todos os exemplos de figura. De qualquer maneira, você não poderia fazer todos os exemplos! Eles saberão readaptar-se a outra solução em outro contexto se tiverem compreendido o princípio de base.

Já Denis, por sua vez, declara:

Antes, eu tinha o sentimento do trabalho bem feito em relação à quantidade de exercícios dados. Mas, na verdade, para alguns alunos, acho que eu não lhes ensinava suficientemente a se virar sozinhos e depois a descobrir outras coisas por uma fase de pesquisa. Agora, faço muito mais matematicamente fases de pesquisa... Agora, dou mais importância ao qualitativo do que ao quantitativo... Se eu quisesse realmente resumir a mudança, tudo continua perfectível, é claro, mas a grande mudança, para mim, é que eles estão mais atuantes. Em muitos pontos particulares, ao deixar-lhes mais tempo e dando mais crédito às suas palavras, faço que eles sejam mais atuantes.

Assim, tanto para um como para o outro, o papel e o lugar recíprocos do professor e do aluno na atividade de aprendizagem mudou. Eles tomaram uma distância, com o cuidado de fazer uma apresentação exaustiva na forma de uma multiplicação dos exercícios e dos diferentes contextos de aplicação dos objetos, operações e métodos. Quer dizer, com as maneiras de agir ligadas à matriz tradicional do gênero "professor de matemática". Puderam integrar, em seu próprio estilo, ou seja, concretamente, em sua própria prática, a questão da atividade do aluno, que até então ficara pouco acessível a eles. Entretanto nem tudo está totalmente solucionado. Assim Denis explica-se com sua antiga maneira de fazer:

Ainda agora, quando penso em algumas classes que tive naquelas épocas, acontece de dizer a mim mesmo: ah sim, quando eu ensinava aquela noção, eles faziam tantos exercícios, eu dava uma série inteira! Estou vendo, e isso ainda acontece. É uma coisa contra a qual tenho de lutar até agora. Só que, agora, lido melhor com ela, encontro outras motivações. Há coisas que faço agora que eu nunca teria feito antes.

Em todo caso, Denis ganhou serenidade, pois ele, que evitava as fases de pesquisa dos alunos, o que o "incomodava", conseguiu estabelecê-las em suas classes. A intervenção lhe permitiu fazer e refazer os liames que tecia entre as situações de trabalho e aquilo que fazia nele.

\section{...para a revitalização dos objetivos da atividade profissional}

A análise, pelos próprios profissionais, de suas variantes estilísticas genéricas, não tem unicamente o efeito de produzir a mudança. Ela permite uma certa revitalização da atividade profissional quanto a seus objetivos. Sobre esse ponto, nem tudo acontece nas controvérsias dialógicas que podem ocorrer nas reuniões dos grupos de trabalho clínico. O processo engloba 
não só essa atividade dialógica, mas também, de maneira indissociável, a principal atividade profissional, a atividade docente nas classes.

É interessante que nos detenhamos sobre um momento desse processo. Denis comenta de novo com Gaëlle o seu antigo curso:

Denis: Tenho outras técnicas que usei depois do que fizemos entre nós [em clínica]. Veja, por exemplo, hoje vamos fazer $(a+b)^{2}$ e sou obrigado a dar alguns exemplos na aula. Eu sei que vou dar exemplos, mas não escrevo nenhum. Digo: exemplo. Meus alunos, que estão habituados porque já faz dois anos que estão comigo, levantam a mão; são eles que têm de me dar os exemplos. Quer dizer que não quero mais, não chego mais dizendo como antes $(2 x+3)^{2}=e$ quando eu os deixava procurar durante trinta segundos. Mas agora, são eles que têm de encontrar o exemplo porque percebi que, ao esforçarem-se para criar o exemplo, eles o retinham.

Gaëlle: Pois é, eles já faziam o procedimento.

Denis: eles já faziam o procedimento de saber quando é que a gente vai aplicar as identidades notáveis. Porque quando eu lhes dizia $(2 x+3)$ ao quadrado etc., depois, num exercício seguinte, eles tinham $2 x$ vezes 3 ao quadrado, eles utilizavam uma identidade notável, ao passo que agora é melhor. Porque quando fazem os exemplos, o que é mesmo bom não é quando eles me dão um exemplo que dá certo, é quando me dão um exemplo que não dá certo. Quando me dizem $(2 x+$ $3 x)^{2}$, eu thes digo, ah, é interessante fazer uma identidade notável aî? Antes, eu não teria feito isso, porque leva tempo demais.

Em seguida, ele acrescenta:

Ah, mas isso tem um efeito, esse gênero de coisas. Nem mesmo imaginamos. É uma coisa que eu fiz um pouco desse jeito por acaso porque, habitualmente, chegamos com exemplos um pouco preparados. Desde que estou fazendo isso, primeiro os garotos se habituaram [ao meu modo de agir] e, depois, habituaram-se a procurar a variedade, a procurar a complicação sem que eu a procure. Acho que, em dez minutos, eu faço muitas coisas que não estão necessariamente escritas, mas, pelo automatismo, isso substitui as séries, substitui o fato de lhes dar vinte e cinco para fazer.

Assim sendo, para ele, essa iniciativa e o seu sucesso constituem um dos momentos da transformação dos objetivos de sua ação que o levou a privilegiar doravante "a qualidade em vez da quantidade", a estabelecer uma nova forma de diálogo com as suas classes em que "a palavra, na classe, está mais liberada. Antes, é verdade, eu sempre interroguei muito os alunos oralmente, mas era preciso mesmo que eu acabasse. Agora, posso dar mais importância à palavra de um aluno".

Com Gaëlle encontramos essa mesma revitalização da atividade principal, a atividade cotidiana:

Eu diversifiquei os meus papeis, isto é, em aulas em que eles trabalham cada qual no seu ritmo com autocorreção, eu me digo que o meu papel é completamente diferente de quando eu dou uma aula na lousa, e eu me digo que o meu trabalho tem diversas facetas. Agora, eu aceito dizer-me, no momento, o meu trabalho não é explicar, porque eu teria sempre tendência a explicar quando vejo um aluno que não compreende. Não, se ele não compreendeu, ele vai ver a correção, o meu papel no momento é dar a todos boas condições de trabalho. Quer dizer, fazer de modo que seja calmo, botar aquele pra trabalhar quando ele parar, mandar aquele outro calar-se, mas que não posso fazer tudo ao mesmo tempo. E eu consigo dizer-me, pois bem, você faz cada coisa a seu tempo. Uma vez, um deles estava me chamando e eu the disse, agora consigo dizer, não, não estou disponivel agora para ir ajudar você, agora, estou cuidando da classe. Mas, antes, eu me sentiria culpada e me diria que ele não compreendeu.

Gaëlle testou outras maneiras de estabelecer e de manter seu diálogo com a classe diferenciando os dispositivos e o seu papel em cada dispositivo. Denis e Gaëlle transformaram, cada qual a seu modo inteiramente singular, sua própria variante estilística do gênero profissional. 
Eles elaboraram novas maneiras de fazer e de conceber o que devem fazer. Daí resultam mudanças de lugar e de papel em suas relações com os alunos, com os conteúdos a ensinar e, por conseguinte, com suas tarefas e suas missões. Essas mudanças revitalizam, em certa medida, sua atividade profissional ao mudar os objetivos e talvez, por um lado, o sentido.

\section{Conclusão}

Como acabamos de ver, os professores de matemática em questão, ao participarem do procedimento clínico da atividade clínica que lhes era proposta, souberam transformar, de maneira sempre pessoal e singular, suas próprias estilizações das diversas versões do gênero que existem em seu meio. Maneiras de conceber, de fazer seu trabalho, modificaram-se nessa ocasião, como também se revitalizaram os objetivos da atividade profissional.

Mas, mais ainda, nesse caso preciso e em algumas outras intervenções que conduzimos, é na capacidade, pessoal e coletiva, de questionar a atividade profissional realizada que se produziram as maiores mudanças. Como disse Gaëlle, por exemplo, ao apresentar sua experiência num colóquio da CORFEM (Commission de Recherche sur la Formation des Enseignants de Mathématiques du réseau national dos IREM):

[Doravante], estamos sempre em questionamento em nosso trabalho, sempre com [a descoberta] de novos conflitos de atividades, de novos empecilhos. O trabalho em clínica da atividade nos permitiu fazer emergirem aqueles problemas do ofício e empunhá-los coletivamente. Então, aparecem, em cada um de nós, outros possiveis, outras maneiras de fazer, de explorar, de adaptar, de tentar, uma fonte de recursos, de gestos, de trabalhos. Evidentemente, cada uma das trocas foi sem julgamentos uns dos outros, sem modelo a seguir, e todos os nossos conflitos de atividades estão sempre sendo trabalhados, em perpétua evolução e em questionamento.

Neste caso, a conduta clínica despertou a genericidade da atividade profissional. Durante sua atividade cotidiana, os sujeitos puderam mobilizar algumas das maneiras genéricas de conceber e fazer, transformá-las e descartar algumas delas. Mas puderam também inventar novas que, enfim, tinham como objetivo trabalhar com a análise e com a transformação do trabalho por aqueles que o fazem.

De certa maneira, parece que estamos assistindo a um afinamento, mas decerto mais ainda, a um desenvolvimento microlocal de uma nova versão de gênero profissional. O problema todo é seu potencial de engrandecimento.

No que diz respeito aos participantes desta experiência, eles estão na iniciativa de verdadeiras controvérsias profissionais entre eles e alguns colegas em sua escola, mas também em diferentes associações ativas no meio docente, agrupando professores de mesma disciplina escolar, ou fundamentadas em escolhas pedagógicas específicas. Ou também em organizações sindicais. Atualmente, estão dialogando com a inspeção regional de matemática a respeito da tutoria dos professores estagiários por colegas experientes, propondo transformar as maneiras de fazer dos tutores e inspirando-se naquilo que eles próprios experimentaram.

Porém, para além dessas iniciativas, que permanecem circunscritas, ergue-se aqui, mais geralmente, o problema dos limites encontrados numa tal versão genérica. Singularmente, os limites postos pelo quadro institucional no qual se exerce a atividade docente. Ele poderia ser um ambiente favorável. Contudo, na França pelo menos, o lugar e o papel dos profissionais, como componentes ativos da definição, das modalidades de exercício e do desenvolvimento das profissões, constitui atualmente um desafio. 


\section{Referências}

Bakhtine, M. (1984). Esthétique de la création verbale. Paris: Gallimard.

Clot, Y. (1999a). La fonction psychologique du travail, Paris: PUF.

Clot, Y. (Org.) (1999b). Avec Vygotski. Paris: La dispute.

Clot, Y. (2008). Travail et pouvoir deagir. Paris: PUF.

Clot, Y. \& Faïta, D. (2000). Genres et styles en analyse du travail: concepts et méthodes. Travailler, 4, 7-42.

Clot Y. \& Roger J-.L. (2005). Généricité et stylisation de l'activité: un exemplo. Cahiers de recherche de l'IUFM de Rouen, 5, 13-26.

Roger J-.L. (2007). Refaire son métier. Essai de clinique de l'activité. Toulouse: Érès.

Vygotsky L. S. (1935/1994). Défectologie et déficience mentale. Neuchâtel, Suíça: Delachaux et Niestlé.

\section{Endereço para correspondência}

jld1.roger@orange.fr

Recebido em: 21/08/2012

Revisado em: 02/06/2013

Aprovado em: 02/09/2013 